\title{
Understanding Econo-Political Risks: Impact of sanctions on an automotive supply chain
}

\author{
ABSTRACT \\ Purpose \\ We introduce econo-political risks (EPRs) to supply chains (SC). Based on case data \\ from an automotive SC, this research identifies the mechanisms through which a subset \\ of EPRs influences SC operations and outcomes.

\section{Approach} \\ An exploratory case study method is employed for theory development. Interviews with \\ SC professionals of three case companies were the primary data source. Company \\ documents, archival records, and direct observation provided further insights into how \\ EPRs are perceived, how they impact a SC, how SC actors react to them, and what the \\ overall performance results are.
}

\section{Findings}

The research identifies EPRs in terms of scope (flow of material, money, and knowledge) and time, and provides concrete examples, along with the channels through which their impact unfolds, and the responses available to SC actors. We find secondary impacts of EPRs through economic and regulatory channels to be significant, and bankruptcy, strategic reorientation, and single sourcing are common outcomes. By elaborating on the mechanisms through which sanctions impact upon supply chains, and the feasible response trajectories, this research can assist SC actors with more effective management of EPRs.

\section{Originality}

This paper is novel for three reasons: first, it introduces EPRs to research into supply chain risk management (SCRM); second, it addresses SC risks in a developing country, a topic largely missing from the literature; and finally, this research focuses on postevent SC risks, whereas the bulk of SCRM literature focuses on the pre-event phase.

Keywords: supply chain management; risk management; disruption; economic risk; political risk; causal diagramming; sanctions. 


\section{INTRODUCTION}

Focusing on developed countries, much research on supply chains (SCs) ignores uncertainties in the political climate due to their secondary importance to the operation of SCs. In practice, uncertainties such as potential restrictions on trade and financial transactions are central to the concerns of many SC managers in developing countries. For example, over recent decades thousands of firms in countries across different continents, such as Burma, Cuba, Iran, Iraq, Libya, Nicaragua, North Korea, and Sudan, have been exposed to significant restrictions due to international and unilateral sanctions. Other firms in countries exposed to civil unrest, drug cartel wars, and insurgencies also have to cope with similar uncertainties.

\subsection{Problem Definition}

We define econo-political risks (EPRs) to SCs as the uncertainty in access to trade routes, partners, knowledge, and financial transactions due to political and economic factors outside the control of the SC members. Besides the directly affected SC members, understanding these risks is of interest to the trade partners of these companies located in other regions. In this paper we elaborate on sanctions, a subset of EPRs and our research focuses on SCs positioned within a sanctioned country. These sanctions are usually imposed on developing countries by sanctioning countries and international bodies in order to achieve a behaviour change in the political or social domain by the sanctioned government.

We use a case study to develop theory around sanctions as an EPR. The case country is a developing country that has faced different levels of sanctions for over three decades. The case study is a car manufacturing SC with different entities, including the manufacturer, a fourth party logistics provider (4PL) and suppliers. The research is based on primary and secondary data: primary data were collected through interviews and observations, and archival documents were used as secondary data sources.

\subsection{Motivation}

The perceived success of sanction regimes as assessed by sanctioning countries and bodies such as the European Union (EU), the United Nations (UN) and the U.S. government partly depends on the lack of ability on the part of the SCs in sanctioned country to adjust to these policies. Therefore, understanding the impact of EPRs on SCs 
is of interest to many players at both the firm and country level. Number of sanctioned countries in Asia, Africa, Latin and South America, and Europe over recent decades includes many dozens and is more than many would perceive (Eyler, 2007); consequently, this is not a rare risk. Moreover, some of these countries are emerging economic powers, which play very important roles in global SCs crossing many boundaries. Therefore, there is a large group of stakeholders who are globally impacted by such sanctions.

Furthermore, research on the impacts of sanctions has so far been limited to the macroeconomic outcomes, and there is little research looking at the level of SCs. The SC level research is needed for building the micro-foundations of macro research on sanctions. More specifically, there has been some research on economic aspects of sanctions in developing nations but impact of sanction on SCs has not been studied in any detail.

Finally, sanctions can be considered as a cause of SC disruption; yet they are qualitatively different from better-researched types of natural and man-made SC disruptions and therefore require separate analysis. Common disasters occur spontaneously and often with little pre-warning, in contrast, precursors to sanctions are observable by SC members long before they are implemented. Moreover, typical disasters are outside of SC members' control; however, the course and severity of sanctions could theoretically be influenced by SC members, e.g. through lobbying activities. Third, natural disasters unfold over a brief time period, while sanctions unfold very slowly. Finally, the impact of typical disasters includes injuries, fatalities, and damage to physical assets, whereas sanctions typically activate very different impact mechanisms.

\subsection{Contributions}

In addition to identifying and elaborating on a distinct type of risk not previously examined within SC literature, this research has additional features that distinguish its contribution to SC risk management (SCRM) literature.

Although SC risk management itself is not a very new research topic in the literature, this paper emphasizes the risks due to political developments, which is less studied. In addition, this research uses data from a developing country, not a common empirical context in the published literature despite the growing volume of global economic 
activity that originates from the developing world. In fact, most of the previous research investigate the uncertainties from the perspective of SCs located in developed countries and may miss important risks faced by a large fraction of global economic actors. The current paper builds on empirical data collected from members of a SC in a developing country. Finally, many research papers over SC risk management comprise pre-event effects but this research focuses mostly on post-event effects including short-term, midterm and long-term effects.

\subsection{Research Questions}

In this paper we focus on understanding the impact of sanctions on SCs. Noting the limited prior research on the topic, we focus on building a better theoretical understanding of EPRs and their corresponding impact mechanisms. We limit our focus to SCs that are not directly the target of sanctions, e.g. our study would not apply to the nuclear industry in a country sanctioned due to a suspected nuclear weapons programme. This is due both to security concerns and the complexities that arise from gaming between political actors, which are not relevant to a typical SC.

We focus on the following novel research questions:

- What are the mechanisms through which econo-political sanctions impact SCs within a targeted country both in the short and the long term?

- What mitigation strategies are followed by SC members in a sanctioned country to deal with the risks imposed by sanctions?

- How does the interaction between these risks and mitigation strategies influence SC operation and performance and how do these influences depend on the position of SC members?

\section{LITERATURE REVIEW}

Most of the literature on sanctions is in the field of political science and focuses on the country as the unit of analysis, thereby not examining the impact of sanctions from the operations management perspective. Nevertheless, this literature provides basic background and definitions pertinent to the current research. A different field of literature in SCRM provides further context and poses analytical questions that we bring into the study of the impact of sanctions on SCs. 


\subsection{Econo-Political Sanctions}

Sanctions include limitations on activities of one or several countries imposed by international players, such as the EU, UN and the U.S. government. These limitations deprive the target country/countries from specific types of transactions. The sanctioning countries and international bodies typically pursue this course to oblige the target country to accept some conditions of the imposing country/body (Eyler, 2007). Depending on the type of transactions they target, sanctions can be divided into categories such as military, economic, international, and political, although some sanctions may fall into more than one category (Charnovitz, 2001; Eyler, 2007; William and Anton, 2003). The post-World War II history has witnessed many instances of sanctions targeting diverse countries, from Argentina and Brazil, to China, Cuba, India, Pakistan, Iran, Iraq, Indonesia, Turkey and many others. In fact, more than half the population of the world has experienced some form of sanctions during this period (Eyler, 2007). This research focuses on econo-political sanctions where the target country is subject to business and financial restrictions, which limit its access to international markets and enterprises. There has been some research on the economic impacts of sanctions in developing nations (Askari et al., 2003; Eyler, 2007) but they have not looked at the impact of sanctions on SCs. Eyler (2007) investigated sixty five episodes of sanctions to estimate the effectiveness of such policies (countries and the sanction period are exhibited in Table 1). Some of these sanctions are still running and some have been imposed on large economies like China, India, Brazil, and Indonesia potentially affecting other SCs in countries not directly targetted by sanctions.

Table 1- Summary of the empirical analysis of economic sanctions by Eyler (2007)

Scope: Macroeconomic aspects of international Main theories for data analysis: Game theory, economic sanctions and public choice theory

Method: Empirical investigation of sixty five cases to estimate the economic, humanitarian and political effectiveness of such policies.

Main recommendation: Sanctions are macroeconomic phenomena that should be analysed similar to monetary and fiscal policies.

\section{Investigated sanction cases:}

Argentina (1977-84), Brazil (1962-64, 1977-84), Cameroon (1992-98), Chile (1965-66; 1970-90), China (1989-98), Colombia (1996-98), Cuba (1960-Present), El Salvador (1977-81; 1987-88; 199093), Ethiopia (1976-92), Guatemala (1977-86; 1990-93), Haiti (1987-90; 1991-94), India (1965-67; 1978-82; 1998-99), Indonesia (1963-66; 1993-95), Iran (1979-81; 1984-Present), Iraq (1980-87; 1990-2003), Libya (1978-Present), Malawi (1992-94), Myanmar (1988-90), Nicaragua (1977-79; 1981-88; 1992-95), Nigeria (1993-98), North Korea (1950-Present), Pakistan (1971-72; 1979-90), Panama (1987-90), Paraguay (1977-81; 1996-98), Peru (1968-74; 1995-98), South Africa (1975-82; 1985-92), South Korea (1973-77), Sri Lanka (1961-65), The Sudan (1989-Present), Syria (1986-94), Taiwan (1976), The Gambia (1994-98), Thailand (1990-93), Turkey (1974-78), Uruguay (1976-81), USSR (1975-83), and Zimbabwe (1983-88) 


\subsection{Supply Chain Risk}

Exogenous events can expose a SC to significant risks. In SCRM literature, disruption is defined as a group of risks rooted in some external factor, such as natural disasters, labour disputes, supplier bankruptcy, acts of war and terrorism (Chopra and Meindl, 2007). Disruption risks generally have a low probability of occurrence but a high potential for great loss (Davarzani et al., 2011). Recently, this research domain has been growing and specialised categories, such as humanitarian logistics in the face of natural disruptions, have emerged (Kovács and Spens, 2007). Many examples of disruptions are discussed within this literature, including the impact of labour strikes and earthquakes on automobile SCs (Kim and Reynolds, 2011), electronics SCs disrupted by fire (Norrman and Jansson, 2004), Hurricane Mitch's impact on banana plantations, and the September 11, 2001 terrorist attacks influence on auto manufacturing in the US (Martha and Subbakrishna, 2002; Monahan et al., 2003) among others.

Research on SC risk and uncertainty management has been growing over the past decade, partly due to the occurrence of major disruptive events such as earthquakes, hurricanes and economic crises. Furthermore, the influence of these events has been magnified as a result of global SCs, which have increasingly alerted researchers and SC managers to the importance of managing these risks. Several models and strategies have been developed for managing SC risks (Hoffman, 2002; Juttner, 2005; Kleindorfer and Saad, 2005; Norrman and Lindorth, 2005; Tang, 2006; Mehari, 2007; Paulsson, 2007). These models typically focus on designing risk identification, assessment and mitigation, and taking proactive actions are recommended to mitigate many of these risks (Norrman and Jansson, 2004; Knemeyer et al., 2009).

Research on managing risks has been typically analytical (Harland et al., 2003; Levary, 2007; Paulsson, 2007; Knemeyer et al., 2009), for example focusing on stylised models of risk management within a buyer-seller relationship (a dyad) and the whole SC (Sinha et al., 2004); however, there are fewer studies on the real world implementation of these models (for exceptions see: Finch, 2004; Kleindorfer and Saad, 2005; Mullai, 2005).

Despite their growing role in the global economy, the state of research and practice on SCRM is less advanced when it comes to developing countries. Data availability and researcher access has limited research focused on these settings. In addition, poor 
management capability and planning processes have also limited SCRM practice in these countries (Blos et al., 2009).

This paper focuses on sanctions, a SC disruption risk that originates from international political developments beyond the control of a focal firm. Research on the impact of sanctions on SCs is very limited and a major reason for this is the complexities involved in accessing relevant data. Access to SCs in countries targeted by sanctions is often limited due to travel restrictions and researcher security concerns. Therefore prior research has not used detailed observations, interviews, or other direct sources of data to elaborate upon the mechanisms and dimensions of sanction risk. In this research we build on a unique opportunity to conduct a detailed case study within a large automotive SC located in a country facing increasing international sanctions. This allows us to assess how in practice SC managers perceive, prioritise and react to EPRs.

\section{RESEARCH METHODOLOGY}

This research uses an exploratory case study method (Eisenhardt, 1989) to develop theory about the impact of sanctions on SCs and the responses of SC actors to this risk. The choice of method is informed by two considerations; first, in the absence of previous research there is a salient need for developing theory on the basic concepts, mechanisms, and variables that are relevant in this problem context and such a theoretical foundation is required for future analytical modelling or empirical testing. Second, a case study is used for theory development both because of the nuanced and multi-dimensional data that it provides through interviews, observations, and archival documents, and because the amount of quantitative data available in this setting does not warrant a data-driven quantitative approach to theory development.

\subsection{Overview of the Case Companies}

The scope of the study covers three members of a SC within the automotive industry, including the main manufacturing company, the only 4PL provider of the focal company responsible for providing parts, and the main supplier of engines, axels and gearboxes. These companies will be termed the 'manufacturer', '4PL' and 'supplier' hereafter. Table 2 provides a brief overview. 
Table 2- Case supply chain characteristics

\begin{tabular}{llll}
\hline $\begin{array}{l}\text { Studied } \\
\text { companies }\end{array}$ & Manufacturer & 4PL & Supplier \\
\hline No. of Employees & Roughly 25,000 & 1652 & Roughly 4,000 \\
\hline Date of launch & 1962 & 1994 & 1993 \\
Responsibilities & $\begin{array}{l}\text { Assembly and } \\
\text { manufacturing }\end{array}$ & $\begin{array}{l}\text { Design engineering, } \\
\text { purchasing and supplying of } \\
\text { automotive parts }\end{array}$ & $\begin{array}{l}\text { Supplier of engines, } \\
\text { axels and gearboxes }\end{array}$ \\
\hline
\end{tabular}

This case represents the largest automotive manufacturer in the Middle East. The manufacturer's main production sites and market are domestic but it has expanded by launching production and export sites in Africa, China and South America, as well as broadening its export market. During the two decades preceding 2011, the focal company has experienced an average annual growth rate of $20 \%$ and as a result the number of its domestic suppliers has increased from 126 in 1993 to 559 in 2011. Although the localisation attempts and the growth of the product portfolio have caused a significant jump from 103 domestically procured parts to 4,500, the company has also tried to expand its international relationships and in 2011 it had cooperative relationships with 264 international companies, mainly situated in France and Germany. Among the global members of the chain, approximately 40 supply parts and the remainder procure licensing, technology and equipment.

\subsection{Primary and Secondary Data}

Semi-structured and open-ended interviews were conducted with SC professionals of the three studied companies in order to understand the current and past state of the companies, the impact of sanctions, and the responses taken by the companies. Company documents, archival data, and direct observations were employed as secondary data sources. Each of these data sources was used in different stages of the research and their uses are illustrated in Table 3. 
Table 3- Summary of the data and their sources

\begin{tabular}{|c|c|c|c|c|}
\hline $\begin{array}{l}\text { Data } \\
\text { Collection } \\
\text { Mode }\end{array}$ & $\begin{array}{l}\text { Total No. of Participants } \\
\text { (and no. of sessions per group and the year) }\end{array}$ & $\begin{array}{c}\text { Average } \\
\text { Length of } \\
\text { Interviews }\end{array}$ & No. of companies & $\begin{array}{l}\text { Focus of Data } \\
\text { Collection }\end{array}$ \\
\hline $\begin{array}{l}\text { Individual } \\
\text { Interview }\end{array}$ & $\begin{array}{l}\text { Manufacturer: Strategic planning vice president (Sep 2007) and } \\
3 \text { managers below him related to risk (Sep 2007, April 2010), } \\
\text { finance (April 2010) and SC (April 2010) } \\
\text { 4PL: manager of foreign procurement (2010), manager of local } \\
\text { procurement (2010), manager of engine group (2007, 2010), } \\
\text { manager of procurement planning (2010), manager of planning } \\
\text { division (2008, 2010), manager of commercial division (2010), } \\
\text { risks analyst (2007, 2008, 2010), manager of localisation (2007, } \\
\text { 2008), manager of supplier logistics (2008, 2009), manager of } \\
\text { production and localisation (2007, 2008) } \\
\text { Supplier*: commercial deputies (2010, on two occasions) }\end{array}$ & 2 hours & $\begin{array}{l}3 \text { (manufacturer, } \\
\text { 4PL, supplier) }\end{array}$ & $\begin{array}{c}\text { Risks } \\
\text { identification, } \\
\text { mitigation and } \\
\text { recovery actions, } \\
\text { mechanisms of } \\
\text { impact }\end{array}$ \\
\hline $\begin{array}{c}\text { Group } \\
\text { Session and } \\
\text { Group } \\
\text { Meetings }\end{array}$ & $\begin{array}{l}\text { Usually } 8-12 \text { persons but the minimum no. of participants was } 4 . \\
\text { Total no. of sessions: } 9 \text { (4PL: } 8 \text { and supplier: } 1 \text { ) } \\
\text { For } 4 \text { PL, different participants in each session but a subset of the } \\
\text { following positions: CEO, head of the } 6 \text { main deputies (planning, } \\
\text { commercial, financial, quality, manufacturing, technical and } \\
\text { engineering divisions), employees in procurement division, } \\
\text { manager of procurement planning, risks analysts, manager of } \\
\text { localisation, manager of supplier logistics } \\
\text { For supplier, participants were the head of } 5 \text { deputies } \\
\text { (commerce, finance, quality, R\&D, technical engineering) as } \\
\text { well as the CEO. }\end{array}$ & 2 hours & 2 (4PL, supplier) & $\begin{array}{l}\text { Mitigation and } \\
\text { recovery actions, } \\
\text { sources of risks, } \\
\text { inter-relations of } \\
\text { risks, mechanisms } \\
\text { of impact }\end{array}$ \\
\hline $\begin{array}{c}\text { Archival } \\
\text { Data from } \\
\text { Companies }\end{array}$ & $\begin{array}{l}\text { Gradually over } 4 \text { years: } \\
\text { more than } 1300 \text { pages }\end{array}$ & - & $\begin{array}{l}2 \text { (manufacturer, } \\
\text { 4PL) }\end{array}$ & $\begin{array}{c}\text { Price of parts, } \\
\text { sources and their } \\
\text { problems, sourcing } \\
\text { process }\end{array}$ \\
\hline $\begin{array}{c}\text { Archival } \\
\text { Data from } \\
\text { Industry } \\
\text { Publications }\end{array}$ & Gradually over 4 years & - & 1 (4PL) & $\begin{array}{l}\text { Background of the } \\
\text { risk management } \\
\text { activities in the } \\
\text { companies }\end{array}$ \\
\hline $\begin{array}{l}\text { Companies' } \\
\text { Websites } \\
\text { and } \\
\text { Publications }\end{array}$ & Gradually over 4 years & - & $\begin{array}{l}3 \text { (manufacturer, } \\
\text { 4PL, supplier) }\end{array}$ & $\begin{array}{c}\text { Companies' } \\
\text { backgrounds and } \\
\text { activities }\end{array}$ \\
\hline \multicolumn{5}{|c|}{$\begin{array}{l}* \text { In addition to the mentioned number of sessions there were } 4 \text { additional sessions (with } 3 \text { procurement employees and the head of } \\
\text { the finance deputy) in which the interviewees did not provide data that was substantively relevant to our topic and thus were } \\
\text { excluded. }\end{array}$} \\
\hline
\end{tabular}

The interview subjects were chosen to provide a breadth of knowledge on the research topic (Yin, 2003). Table 3 provides a summary of the different data items collected and their sources. The companies were aware of the research topic and supportive of it due to their major concern regarding risk management in the face of sanctions. Open interviews with three high-ranking executives of the investigated companies were conducted to establish the research scope and focus. Furthermore, thirteen executives and seven of their direct reporting employees were interviewed using a semi-structured interview protocol (see Appendix A) with the goal of identifying different types of EPRs due to sanctions and the firms' responses. These interviewees covered the 
relevant decision makers in the SC when it came to assessing the risks and responding to sanctions. Four of the managers were interviewed as a group because of their complementary knowledge on different aspects of the risks. In total, 31 individuals were interviewed with some informants being interviewed more than once. Four individuals have been excluded from Table 3 since the interviews demonstrated that they were insufficiently informed about the research topic. Interview questions were focused on EPRs, so interviewees needed to have specialized knowledge about the topics in the meeting. Note that, all the key informants of the studied companies were interviewed either individually or in focus group sessions. A summary of each interview was shared with the interviewees for edits and confirmation of accuracy.

In addition to the individual interviews, nine focus group sessions were organised to gather the required data on mitigation and recovery actions, sources of risks, interrelations of risks, and mechanisms of risk impacts. Furthermore, data was collected from current documents published by the organisations, including demand, price list, and the quality cost of some of the internationally sourced parts. Figure 1 summarises the research steps and related data gathering efforts. More elaboration on the data analysis method is given in Appendix B.

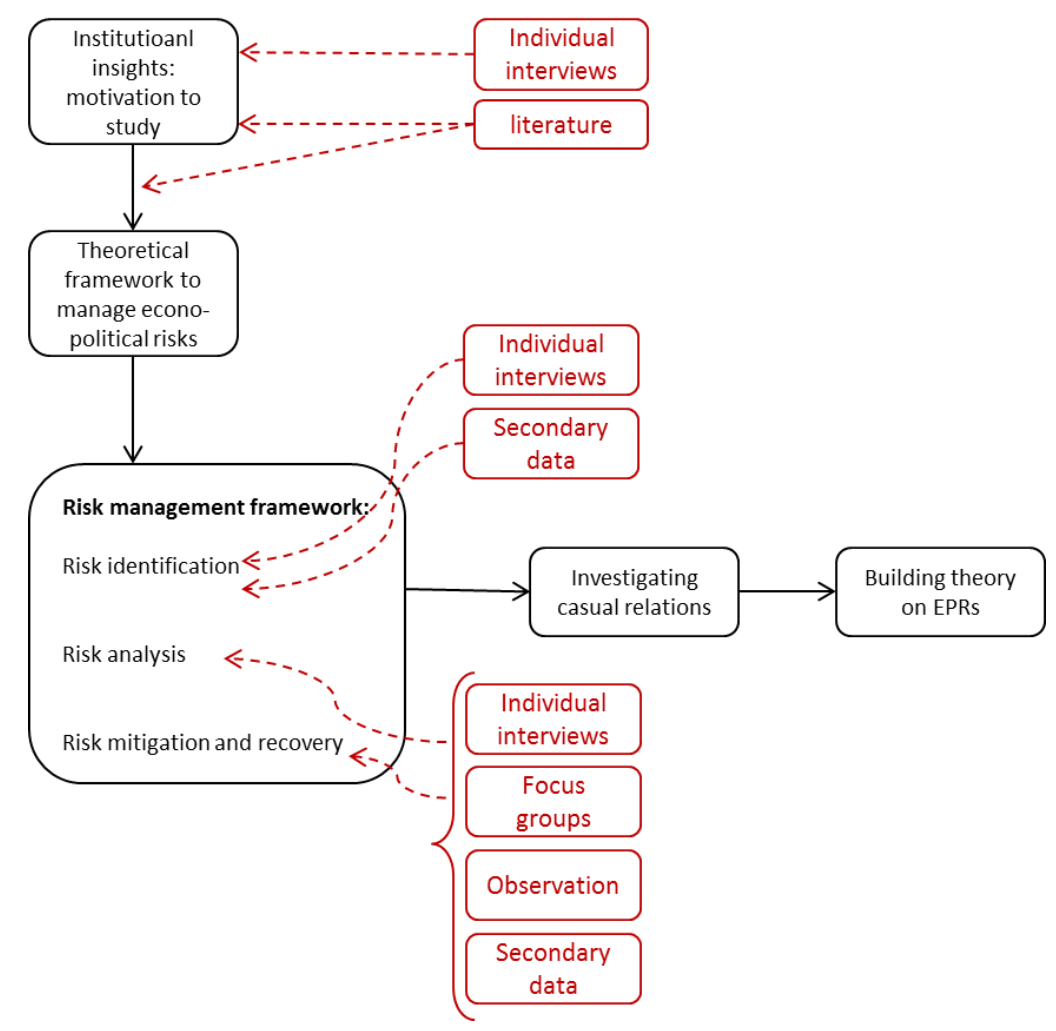

Figure 1- Research steps and the data sources for each step 
The research lasted for four years and as a result different individuals occupying the same roles were interviewed in a few instances and this led to additional insights into the impact of variations across individuals on risk assessment and responses. Because of the longitudinal impacts of sanctions we needed to study the case for a long time horizon to be able to capture important impacts and solutions spanning a few years.

The data collection and analysis process follows a qualitative research method, draws upon different sources, and spans multiple years. These factors increase the need for a rigorous research process to ensure that the findings are reliable. Several steps were taken to address this issue, multiple criteria were explicitly considered to enhance the rigor of qualitative case studies (Mollenkopf et al., 2007; Lin and Zhou, 2011) and applied in the design and implementation of the research. These criteria and the specific actions related to them are summarised in Appendix C.

\section{DEVELOPING THE THEORY ON THE IMPACT OF SANCTIONS ON SUPPLY CHAINS}

A theory on risks of sanctions on SCs is developed in the following steps. First, an organising framework of risk management is offered, which informs the relevant components that should be addressed in our theory. Taxonomy of EPRs and a map of the typical menu of responses at the disposal of affected SCs are then provided. These components are substantiated by mapping out the risks faced and the responses adopted in the case studies, along with their impacts on the overall SC.

Sanctions are a prime example of EPRs. Firms in a targeted country may be affected through multiple channels, but the exact pathways, the extent and the duration of the impact are unknown. These uncertainties are a major concern and firms may need to plan for alternative contingencies that may unfold. In fact, the uncertainty is potentially higher in industries that are not a direct target of sanctions. In these cases, many unforeseen effects of sanctions are likely to catch managers by surprise, significantly increasing the risks these managers face. As a result, we draw upon SCRM as the underlying theory to organise our concepts.

SCRM literature offers several different risk management frameworks (Harland et al., 2003; Sinha et al., 2004; Juttner, 2005; Kleindorfer and Saad, 2005; Knemeyer et al., 2009). While they differ in details, three steps concerned with risk identification, analysis, and planning/implementation are shared across these frameworks. Moreover, 
risk management is a continuous process that is maturated over time (Finch, 2004; Norrman and Jansson, 2004); therefore we conceptualise this process as a three-step cycle (Figure 2), which needs to be customised based on sub-steps for different groups of risks or business types. Analysis and planning for the management of operational risks are inherently different from disruptions, and within each of these groups of risks every single type of risk calls for tailored actions.

Through our first phase of interviews and the review of the literature, we identified the scope of the risk, its timeline, and its impact type as useful dimensions for organising EPRs. The scope of risk captures which of the central flows in a SC, i.e. money, information and material, can suffer from a risk item. While much of the disruptions discussed in the literature focus on material flow, EPRs can also significantly impact on money and information flows. Impact type signifies the specific operations that are impacted by a risk item. Furthermore, in contrast to typical natural disruptions that unfold quickly, EPRs unfold slowly and therefore their timeline is a distinct factor to be considered. We categorise EPRs' impacts into short term and long term, where the former appear within one year after imposing new sanctions and long-term consequences are revealed over a longer time period.

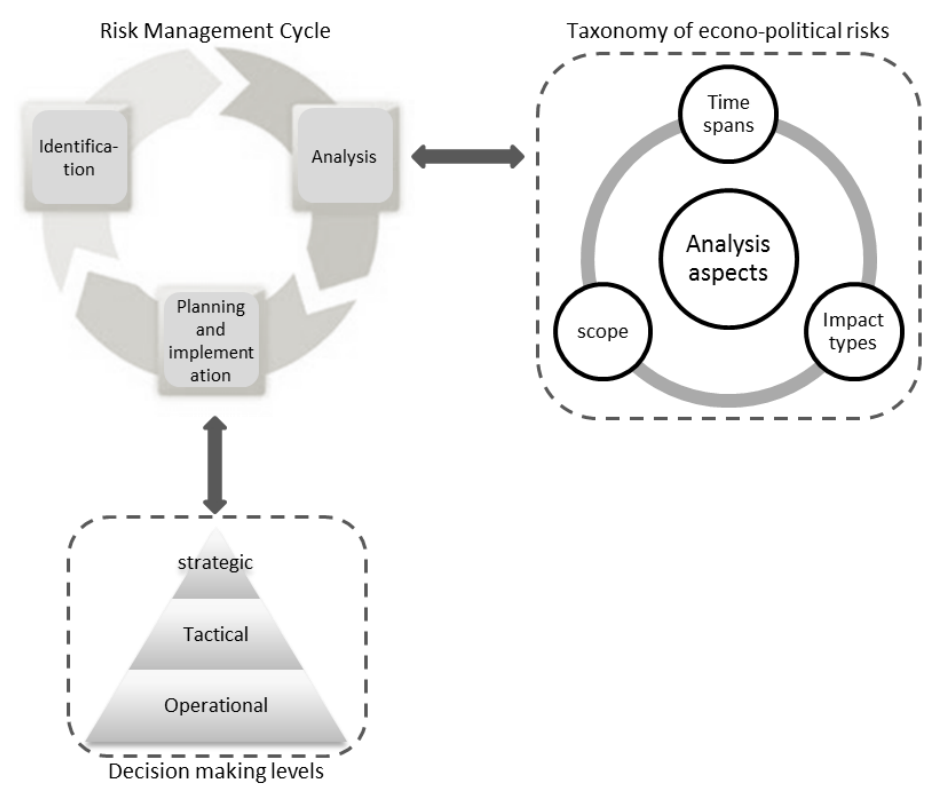

Figure 2- Theoretical framework to manage econo-political risks 
In response to perceived risks the SC actors may react at different levels, operational, tactical, and strategic. Operational responses address an immediate problem, tactical responses are taken to adjust SC operations in line with the medium term repercussions of the risk, and strategic changes will be considered if operational and tactical steps cannot solve the long term problems caused by EPRs. For example, in June 2010 the 4PL company suddenly faced a sanction-motivated prolonged inspection time in the Netherlands for a part that was sourced from there. It had been planned to transport the cargo to the destination by sea and the increased lead-time could have caused significant production delays. The immediate operational response was to transport a batch of products by plane at a significant shipment cost. This operational activity triggered a tactical change to the production schedule and the company used for shipment. Repetition of such problems can initiate adjustments in sourcing strategies, for example seeking alternative sources from a different country or continent.

\subsection{Taxonomy of Econo-Political Risks}

EPRs have a widespread impact on business. Gathered secondary data from the case and primary interviews with informants revealed significant effects of such risks on expected demand and production. Even though the studied SC was not directly the target of sanctions, it has suffered significantly as a side effect. In fact we first performed a pre-study to identify potential SC risks in the studied case, which highlighted sanctions as the most important source of risks, when taking into consideration the probability and severity of impacts.

Focus group sessions let us identify multiple instances of EPRs, and revealed their multi-dimensional nature. The main emphasis of those meetings was to gather deeper knowledge about how different types of risks occur, how they influence the business, what factors are important to consider while analyzing them, how supply chain partners have tried to manage such risks in the past, and what other mitigation efforts are being considered by the case companies. Based on the focus group meetings, we identified the scope of the SC that was at risk as an important dimension. Specifically, the flow of knowledge, finances, and material could be impacted by EPRs (Figure 3). Within each of these groups we identified additional types of impact that captured the key risk factors. We also found it useful to distinguish between short-term (less than one year) and long-term impacts. Whereas short-term impacts are typically seen to require urgent 
fixes to avoid operational failures, the long-term risks change the strategic direction of a firm, e.g. in product choice, balancing innovation and production, export goals, and market segmentation. In practice, we found that most common elements of sanctions e.g. resolutions by the $\mathrm{UN}$ or EU, first impact financial flows, and then become significant impediments to material and knowledge flows, partly as a result of disruptions in financial flows.

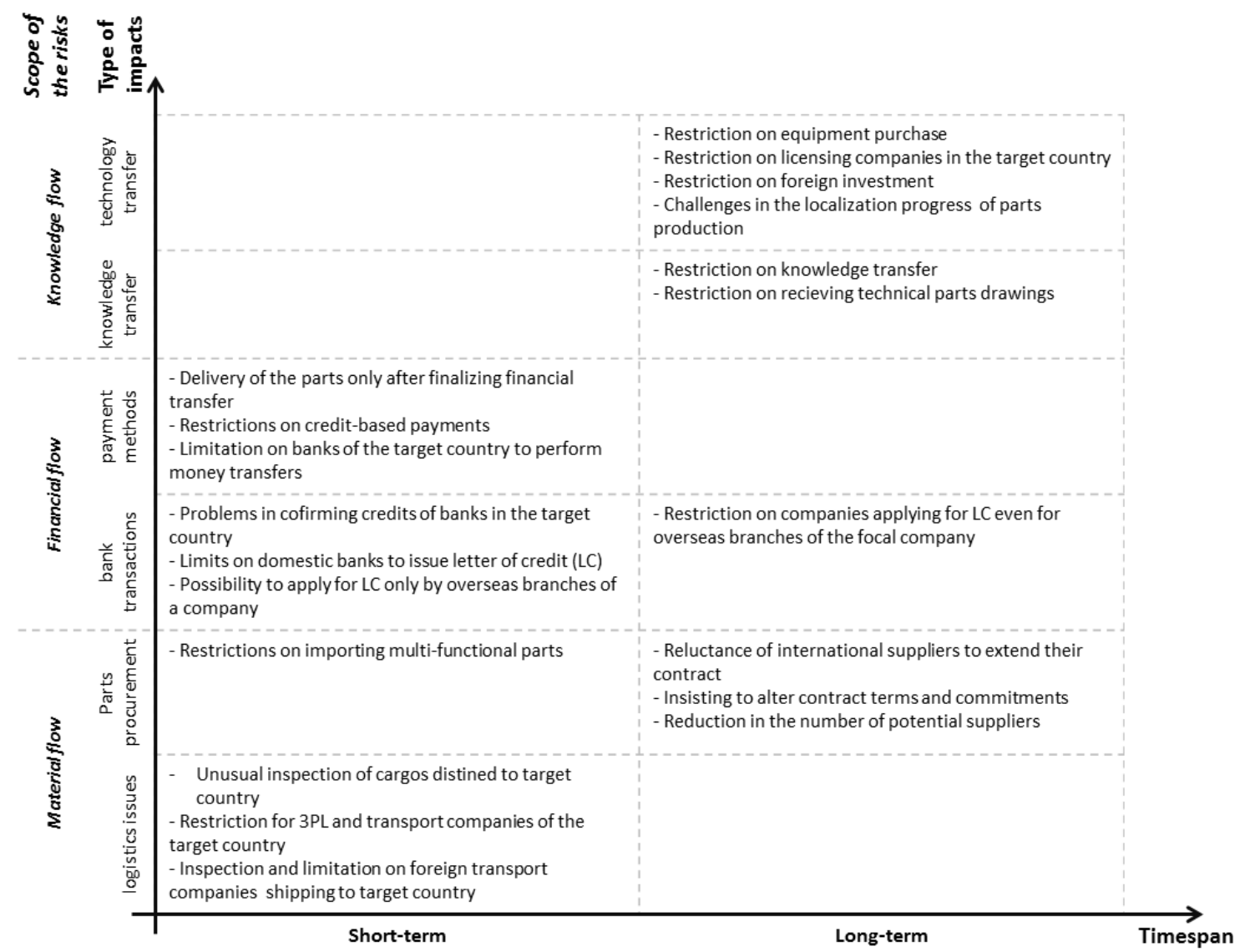

Figure 3- Classification of the econo-political risks based on time span, scope and types of risks

Different types of risks are relevant within each impact scope. Material flows may be disrupted due to both part procurement and logistics effects. In the short run the logistics issues are the most salient, and include inspection, third party logistics (3PL) providers and transport company restrictions, and restrictions on foreign transport companies. For example, at the first sight a 2006 resolution banning the 'export/procurement of any arms and related material' to the target country may sound irrelevant to the automotive industry; however, enforcing this ban has led to random 
inspections of cargos destined to the target country. Shipments of automotive parts may fall under these inspections, leading to weeks of delays in shipment. Variations in inspection frequency and rigor create variations in risk across different source countries. Due to the language of the sanction laws or their interpretation by enforcing countries and entities, other restrictions may be imposed that prevent 3PL providers and transport companies of the target country from utilizing some routes and origins. Ultimately, restrictions on foreign 3PL and transport companies to perform shipment for companies of target country may be introduced leading to acute procurement challenges. While the stated banned parts may be limited to those with military usage, some automotive spare parts are suspected to have dual use. Such parts may include many generic parts, such as specific types of bolts and screws. Suppliers may supply these parts, but they should ensure their usage is in non-military applications, requiring primary and follow up checks on their usage in the production line of the buyer. Problems exacerbate over the longer term as suppliers of such parts may insist on terminating the contract or altering delivery commitments and pricing. The reduction in the number of willing suppliers also reduces the negotiating power of the buyer, leading to further costs. Consequently, the buyer should either pay more, seek alternative parts that are not dual-use, or modify the strategic direction of the products portfolio.

EPRs impact financial flows through payment methods or bank transactions. Bank transactions central to trade, such as obtaining letters of credit, confirming credit, and executing money transfers, could all be impacted. Sanctions may target these bank transactions directly, for example financial institutions and banks of the target country may be banned from some transactions, or international financial institutions may refrain from working with such entities for fear of triggering sanction-related penalties. These factors usually kick in as the knowledge of sanctions and their potential risks for financial players become known internationally and new more restrictive processes and guidelines are developed by international partners of the target country. These limitations may force SC actors into cash transactions, which increases transaction costs, reduces flexibility, and lengthens transaction times. In fact, some trade partners may lack specific procedures to execute large cash transactions. As a result, not only do the direct transaction costs increase, but also SC members are forced to keep more inventories or face additional uncertainty in production. 
The impact of EPRs on knowledge flow surfaces over longer time horizons and can influence the capability building in SC member companies. While the sanctions in our case do not target knowledge transfer to the target country, many countries and authorities interpret the ban on knowledge related to military and nuclear programme extensively to include licensing, technologies, and knowledge relevant to automotive SC. This can complicate the response efforts by the SC actors. For example in response to part shortages due to material flow disruption the manufacturer had attempted to develop local suppliers. However, this process was partly hampered by restrictions on licensing, trading equipment, and technology transfer. In addition, the SC had to slow its growth programme as it could not easily expand and alter its product portfolio due to the restraints on buying equipment, foreign investment and knowledge transfer.

An additional finding from our case is that EPRs can trigger regulatory and public responses with a potentially significant impact on the SC. These secondary effects of EPRs are often varied and may include both challenges and opportunities. For example, a target country may change its regulations to adapt to some of the consequences of the sanctions, which may have positive and negative ramifications for the SC in question. In our case, the government's concern about inflationary results of sanctions has increased the risk of imposed price controls on the automobiles produced in the country. However, the sanctions have held back the country from joining the World Trade Organisation and thus have kept high import tariffs on automobiles, thereby allowing domestic car manufacturers to survive international competition despite their inefficiencies. Moreover negative economic impacts of sanctions, and the risk of the extension of sanctions to gasoline imports, has increased the long term appeal of fuel efficient cars, changing the strategic demand outlook for the SC in question. Overall, whilst the net impacts of the secondary effects of EPRs are somewhat ambiguous, their extent can be significant, thus leading to major uncertainties for the SC actors and increasing the risks regarding long term investments.

In contrast to natural risks, EPRs emerge slowly. Our case SC was exposed to low levels of these risks for over two decades yet grew at an annual rate of $20 \%$. Economic stakeholders across political fault lines often resist the escalation of EPRs and may succeed in containing these risks. However, political developments can escalate the risks and lead to full-fledged EPRs, as has occurred since 2006 in our case. Once in place, the removal of these risks may be complex and partly dependent on their scale or 
original cause. Political developments can de-escalate tensions that had led to the EPRs in the first place; however, this may not be enough for the reversal of EPRs. Once trade links are severed, many international players with stakes in maintaining the trade routes lose interest as they establish a new trade portfolio. Others may institute organisationlevel policies that block potential transactions with a target country. In the absence of pressure from these international players it may take a long time, even years, after the end of a political conflict before EPRs such as sanctions are completely resolved.

\subsection{Factors Moderating the Impact of EPRs}

While EPRs are not directly controlled by the firm, our interview findings pointed to exposure of a SC to international trade as the main moderator of the impact of EPRs on a SC. This moderator also highlights the strategic reorientation a SC may need to undertake in order to minimise the impact of EPRs. Product characteristics partially explain the exposure of a SC to international trade. The ease with which products, including spare parts and procured material, can be domestically produced reduces the potential impact of EPRs. In practice, different products in the portfolio are differentially exposed to international trade, and the increased probability of EPRs may shift the strategic focus of a company towards those products with lower exposure. In extreme cases, many items in the portfolio may become infeasible to produce, reducing the choice set for the SC and significantly hurting both profitability and robustness against other risks.

The technologies used in the production process are also directly relevant to these considerations. Production processes that rely on imported manufacturing equipment or know-how are more exposed to EPRs. This risk extends to different suppliers of the SC, so in practice some of the more advanced and financially strong suppliers, who traversed the technological frontline before sanctions, become more at risk in the face of EPRs. In contrast, larger and financially stronger suppliers are more resilient to demand fluctuations and payment delays. Other characteristics of existing and alternative supplier networks also play a moderating role. Where a manufacturer has access to multiple alternative suppliers, especially ones that are not solely tied to it (and thus can more flexibly accommodate changes in demand), it is more resilient in the face of EPRs. 


\subsection{Response to the Risk: Planning and Implementation}

The response of SC members to EPRs varies depending on the actors' perceptions of timing and scope of the risks. The impact of these risks unfolds gradually, potentially offering SC members time to plan and take precautionary actions and responses; yet SC members may still be caught by surprise. For example, one of the significant EPRrelated disruptions in our case dates back to December 2006, when a new UN resolution temporarily cut the supply of a critical part and shut down a major production line. SC decision makers were caught by surprise because over the previous decade they had seen several sanction laws with limited impact on the automotive industry. In response to this event a risk management team in the SC was created to focus on the analysis and planning for possible risks.

However, EPRs are not easy to plan for and in fact we observed few proactive moves by the SC to prepare for these risks before they emerged. EPRs typically arise from the political sphere and are part of a complex game between different international players, and as a result many future steps are hard to predict. Even when sanctions are in place, they may not be enforced in one period, followed by overenthusiastic enforcement in the next period. In the face of these uncertainties we found that SC members were reluctant to take extreme actions and preferred to adjust their reaction to the actual level and persistence of a challenge. In fact some solutions require strategic reorientation and are only advantageous if the sanctions are persistent. We therefore, categorise the actions of SC companies in face of EPRs based on the decision making level, which also largely corresponds to the time horizon for a decision (See Figure 4).

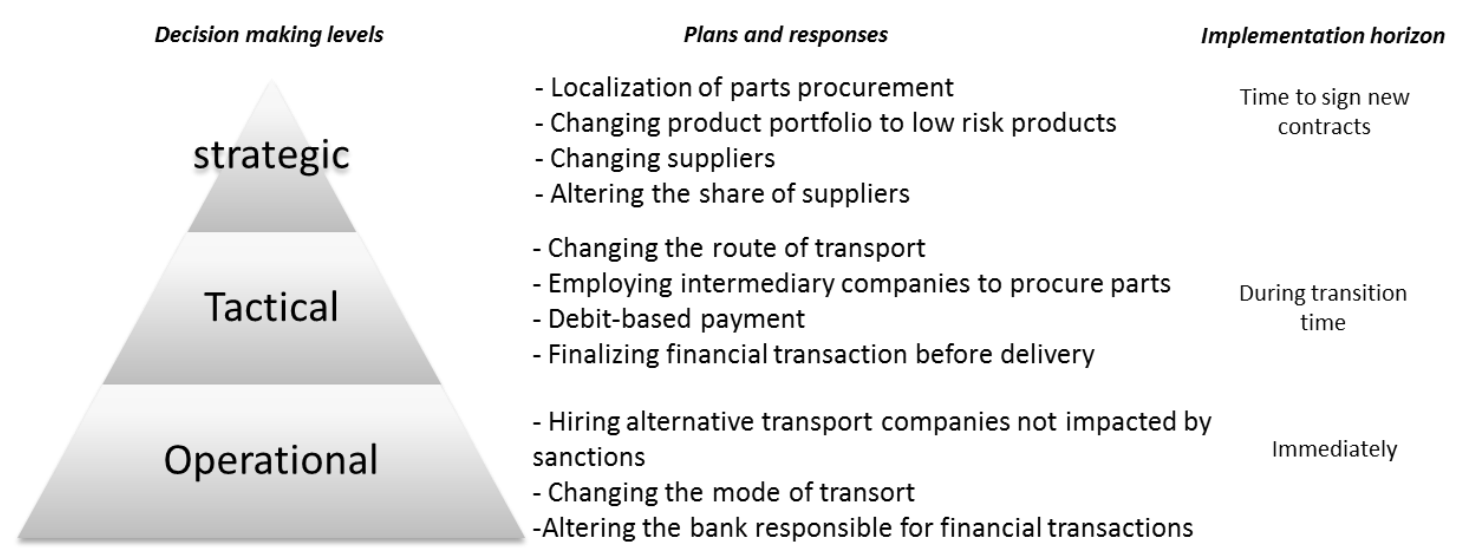

Figure 4- Decision making levels 
The most common operational response included finding alternative ways to complete a blocked transaction. In some cases the transport mode was changed from ship to air to avoid delays in the shipment of critical parts due to unexpected inspection delays. The SC also resorted to hiring more expensive international transport companies in the face of this risk. Finally, in a few instances financial transactions were moved to alternative institutions when the responsible bank in the target country was blocked from conducting international transactions.

Once the immediate challenges were resolved, tactical moves were pursued to further mitigate the risks. We observed a few of these moves that occurred more frequently in our cases: transport routes were changed to avoid future inspection delays; intermediary companies in third countries were set up to handle the routing of the goods without triggering sanction related alarms; and financial transactions were increasingly handled based on debit, e.g. cash, and by full payment before the shipment of goods.

At the strategic level we observed a few responses that the case SC relied upon, including localisation, altering of the product portfolio, incorporating low risk global suppliers, and altering suppliers' share. Enlarging the domestic share of supply was an increasingly important strategy over the study period. This strategy was also advocated by the national government, which sought to address unemployment (partly attributable to sanctions) through increased domestic production of intermediate parts. A shift in the product portfolio was also pursued to accommodate products that are less reliant on an international SC. In our case the production plans for seven alternative car platforms could be changed to move production towards lower-priced products, which included fewer internationally sourced parts. Such shifts, however, are also bounded by demand for these products that is influenced by EPRs.

Another strategic reorientation included efforts to replace or add alternative global suppliers with higher reliability in the face of sanctions. In practice this required shifting towards suppliers in East Asia. The downside of this shift was the lower quality in the procured parts compared to the original parts produced in Europe. In fact, a committee was formed to identify critical parts and potential suppliers, and to negotiate flexible contracts with them that allowed the SC to quickly shift to these alternatives in the face of new disruptions. 
Consider a concrete example: in 2010 the higher management of the manufacturing company, recognising the gravity of the EPRs, significantly lowered its expected demand and thus the production plans for the upcoming years across all the production lines, as illustrated in Figure 5. The new plans reflected the confluence of multiple factors: the general decline in buying power of the population was expected to reduce the demand and shift it to the cheaper product segments; and production costs were expected to rise significantly across the board with a larger impact on the higher end products that relied on part imports. In fact, the feasibility of high volume production was questionable for some high-end segments and domestic sourcing was put forward as a strategic priority. These factors contradicted the original strategic plan to cut down production on SM1 and SM2 entry segments and move towards high-end segments. Another conflating factor was the expected government budget deficit, partially due to sanctions, which was anticipated to cut back on the decade-long 'cash-for-clunkers' programme that had assisted low income individuals in buying entry level cars (SM1 and SM2 segments). Finally, while reducing the expected innovation rate in the highend segments, the management increased the share of dual fuel models, cars able to burn both natural gas and gasoline, across the board, to address risk of gasoline shortage due to sanctions.

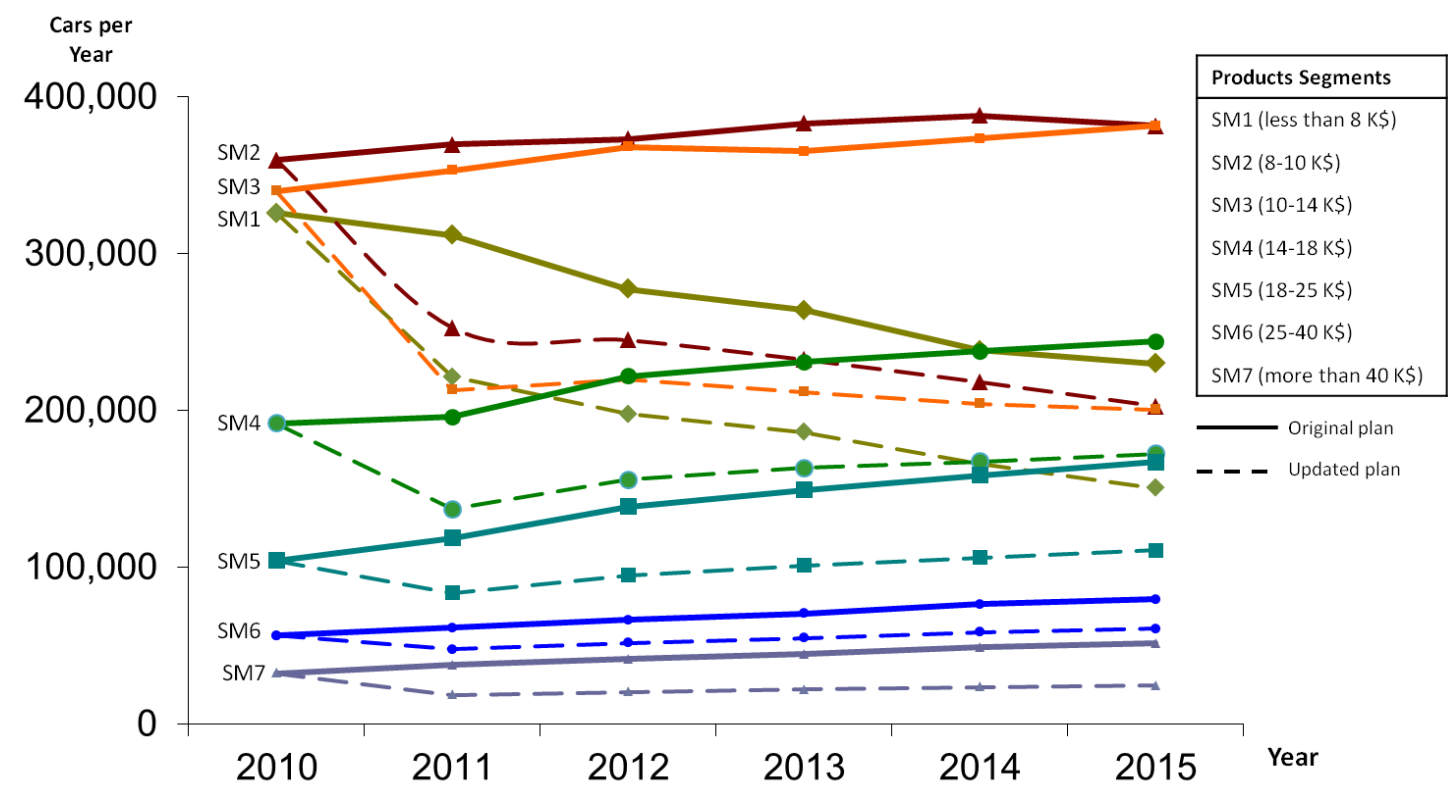

Figure 5- Changes in predicted demand and production plan for the five year horizon following the accumulation of EPR-related strategic considerations in 2010. Dollar values for product segments are based on 2010 exchange rates, which changed significantly over the 2011-2012 period. 
The implementation of these changes could be complex. Our informants agreed that smaller companies often lack the expertise, connections, and financial slack required for implementing some of these changes, especially those at the strategic level. As a result, they may try to use operational shortcuts, such as using incompatible parts, thereby leading to significant quality problems downstream. Inability to cope with these risks has also lead to the bankruptcy of many smaller suppliers. In fact this effect is increasingly reducing the options for domestic sourcing of the parts, reducing the longterm viability of the strategy that was originally favoured by the SC players.

\subsection{Integrating Risks, Responses, and Downstream Effects}

Results of the group sessions, individual interviews and reviewed documents were integrated to develop a qualitative model of hypothesised causal pathways through which EPRs impact the SC. These pathways are discussed in the text and a summary influence diagram (Sterman 2000) is available in Appendix D. Specific EPRs and the responses taken by the SC in each case have been discussed above, yet several downstream effects require further elaboration. In many instances responses that helped alleviate the EPRs entailed some costs and side effects, which were important in our case. Quality was hurt when sourcing was shifted to domestic suppliers or those with more lenient policies regarding the enforcement of sanctions. Contracting intermediaries, using cash payments, changing transport routes, and working with international banks, all increased the lead time in part procurement and elevated production disruption risks while also incurring additional inventory costs. Contracting intermediaries and international transport and 3PL companies, changing transport routes and modes, as well as cash payments also increased the overall import costs, thereby damaging the financial viability of both the suppliers and the manufacturer.

Poor or incorrect parts, due to single sourcing, domestic, or low quality replacement suppliers, increased the production disruptions, as did increased part lead time and supplier bankruptcy, which was becoming increasingly frequent. Investment and maintenance costs were also increased when restrictions on foreign investment, knowledge transfer, and equipment import were put in place. Lower quality, production uncertainty, and increased costs all significantly hurt the financial health of the manufacturer. 
Several secondary effects of the sanctions were also notable. In addition to the direct impact of the sanctions on the studied SC, they have also had a broad influence on the business environment. For instance, sanctions in the country of this case have resulted in a significant limitation on fuel imports. Domestic petrol producers have limited their production capacity and the country is highly dependent on the import of fuel. Designers of sanctions tried to persuade the target country to accept their conditions through imposing a severe prohibition on fuel trade. This restriction has led to a rise in the fuel price in the national market and a shift in demand towards more efficient cars. This was exacerbated by an overall economic downturn, partially induced by the sanctions, which further reduced overall demand. These shifts, along with barriers to imports and exports and the loss of research and development growth, have forced the manufacturer to downgrade the product portfolio towards cheaper and more domestically supplied products. This has reduced the profit margin and overall revenue, further hurting the bottom-line.

A further impact of the sanctions on the business environment can be observed when considering their impact on broader economy. The studied SC is located in a country with oil resources. Oil export plays a crucial role in balancing the economy of this country. Sanctions induced restrictions on the export of oil, a reduction in oil revenues, and consequently an increase of the exchange rate, thus increasing the costs of imported parts further and cutting the government's revenue. The latter effect reduced the availability of government loans for the SC actors. In the absence of these loans, and faced with a manufacturer who was financially in trouble and thus late with payments, some suppliers went bankrupt, putting further pressure on the manufacturer in a vicious cycle.

We also noted that EPRs could indirectly challenge the application of rational decision making processes in the SC, thereby weakening the SC's ability to cope with these risks. For example, in response to the sanctions the national government resorted to different measures, these ranged from a denial of the risks (in order to keep domestic support for contentious international policies) to the censorship of news related to the impact of these risks, and manipulation of the currency markets. These measures increased uncertainty and reduced the clarity of communication and openness of planning processes among the larger members of the SC. In fact, with many dependencies on the government, a manufacturer could be forced into taking actions 
motivated by political considerations rather than the financial interests of the shareholders. In the longer-term, the declining business environment persuaded many talented human resources to emigrate from the country, further eroding the capability of SC to manage the risks and mount viable response. These indirect challenges to functional decision making were increasingly significant with the escalation of EPRs. It is plausible that $\mathrm{SC}$ members also put pressure on the political decision makers to take steps towards reducing the EPRs; however, our research did not provide opportunities to document these potential balancing effects.

\subsection{Overall Impact of Econo-Political Risks}

Precise evaluation of the impacts of these causal mechanisms on the SC in question is complex and requires data beyond that available in our case study; however, we can offer some basic observations. Due to international political dynamics the EPRs were ramped up over the 2006-2011 period in our case. Initially, the fixes applied by the SC members were sufficient to mitigate these risks and the financial impacts were rather limited. After an initial surprise the SC members became adept in identifying the risks and ways to go around them. However, in the latter half of the period the long term impacts and the side effects of initial fixes started to kick in, while the scope of sanctions continuously expanded. At this point the SC became trapped between restrictions on the flow of material, money, and knowledge, and the macro-economic and demand side effects of sanctions. Thus the EPRs started to take a significant toll on the SC despite the different contingency planning that had been undertaken. In fact, if it was not for the high tariffs imposed on automobile imports to support domestic production, the whole industry could have gone bankrupt in competition against international players.

\section{IMPLICATIONS AND CONCLUSIONS}

In this research we have used a case study of a SC in a country under sanctions to enhance our understanding of EPRs to SCs and how a SC reacts to such risks. The theory we have developed highlights the different pathways through which these risks influence a SC and the different solutions SC members employ to mitigate the risks. We found it helpful to organise the types of risks based on the time frame during which they unfold and the scope and types of activities they target. Furthermore, we organised 
potential risk reactions in terms of the implementation time horizon and the level of decision makers within an organisation that they involve.

Overall, EPRs are somewhat unique in that they are slow moving, may change in response to the reactions of SC members, and may influence a large number of SCs regardless of the industry and even geographic proximity. Once exposed to such risks SC members may have to move slowly in their responses because all solutions are costly and changes in the political atmosphere may alter or remove the risk before a long-term solution can be implemented. Once established, however, these risks are persistent and significantly erode the profitability of SC members. Most affected are the small suppliers at the bottom of the chain who lack the financial resources, the network and expertise, and the political connections needed to manoeuvre around these risks.

\subsection{Theoretical Implications}

Our paper distinguishes EPRs as a major category of risks to SCs not previously studied. EPRs affect different aspects of SC operations. Results of the analysis suggest classification of these impacts based on their scope (material, financial and knowledge flow) and time span (short-term and long-term). Material and financial flow are immediately influenced by EPRs, while the impact on knowledge flow can mainly be captured when SC operations are investigated from a long-term perspective. The magnitude of these impacts can vary significantly based on the focus of the EPRs and according to their importance within different industries. For the companies similar to the studied case in this research, a high level of international connections and dependency is a liability that exposes the chain to EPRs.

Unlike most SC risks, EPRs emerge slowly. Over two decades of exposure to some sanctions had limited impact on the firms we studied, potentially making them less sensitive to increasing risks as new sanctions were put into effect from 2006 onward. Once these new sanctions were in place the firms started to undergo a large number of changes in response to, or as a result of, these sanctions. Furthermore, EPRs long-term impacts are mainly related to restrictions on knowledge and technology accumulation, which limit the growth of a business and its strategic position in the global market.

Sanctions also indirectly influence SCs through changing the business environment. In our case country the increase of fuel price, significant fluctuations and a sharp increase in exchange rates, and the reduction of oil exports and consequently lower oil revenue 
for the government, were among the key general effects of sanctions that radically changed the business environment. These indirect effects are a major part of how EPRs influence SCs.

Reaction of supply chain members to EPRs is changing through the time from the start of the threats. This paper categorizes reactions/mitigation strategies into operational, tactical and strategic levels. SC members initially react to these risks by trying to circumvent the threats and then by changing their strategic direction to reduce exposure to these risks. When sanctions were first imposed SC members employed operational and temporary solutions. Once they suspected that the sanctions would be in place for a long time then strategic changes were adopted.

The presented framework and theoretical structure will allow researchers encountering a new problem to better articulate the scope, timeline, and type of risks as well as the mix of responses the SC members may draw upon. They can also use the proposed causal mechanisms to trace potential processes that may be operational in a new setting, to conduct quantitative risk assessment, and project future scenarios.

Our research underlines the interdependency of EPRs. Whereas SCRM literature often focuses on a specific risk and how to manage it, we find that EPRs are interlinked, emerge in parallel, and their solutions are also interacting. This calls for more holistic modelling and analysis in the evaluation of EPRs and their impact. We also observe the propagation of risks across members of a SC to those not directly exposed to EPRs, a finding that may apply to other types of risks as well (Wu, Blackhurst et al. 2007). A new dimension of risk propagation that we find to be important is when a SC is exposed to economic and regulatory risks that are secondary effects of the original EPRs.

Two novel characteristics of this research complement its contribution to the SCRM literature. First, the majority of SCRM research focuses on the pre-event phase of the risk management cycle but this research focuses on the post-event effects and reactions, including both short and long term dynamics. Second, the majority of empirical research on SC risks and disruption are based on data from developed countries, whereas a growing share of global production and trade belongs to SCs that involve developing countries. Research in these settings is impeded by data availability and access to stakeholders, yet new insights regarding how real SCs in developing countries 
work, what their common challenges are, and how they could be improved would make such research worthwhile.

\subsection{Practical Implications}

Besides elaborating on the basic concept of EPRs and their implications, this paper has potential ramifications for different players. Members of SCs in countries with a high risk of sanctions can learn to navigate this risk by knowing about potential solutions they can include in their response portfolio. These include actions such as re-routing the transport path, employing intermediary companies, and having a supplier contingency plan. The usefulness of these actions depends on the type of threat and its persistence. The research also provides insights for market players who may want to turn EPRs into commercial opportunities, as SCs in sanctioned countries are seeking international partners to soften the impact of such restrictions. By understanding the causal mechanisms that regulate the impact of EPRs, potential external partners may identify unique business opportunities sought by SCs exposed to EPRs.

This research can also inform the design of smarter sanctions as the focus of this article is on SCs that are not directly the target of sanctions. In our case and during the time period of this study, none of the sanctions imposed on the case country were supposed to be targeting the SC in question. However, in practice they significantly influenced the SC leading to the bankruptcy of a sizeable number of smaller private suppliers, and in balance resulted in much collateral damage. Helping understand the hidden costs of sanctions is important in evaluating and designing sanctions. In fact, one of the main debates within sanctions literature is how to improve the effectiveness of sanctions (Eyler, 2007). The primary reason for sanctions is to force countries to change their behaviour by causing commercial barriers and financial problems for governments. However, if sanctions weaken the private sector (which is often in competition with the governmental sector, especially in developing countries), they may actually increase the relative power of a government, thus reducing the effectiveness of the sanctions. The insights of this research help to distinguish between planned impacts and side-effects of sanctions. Moreover, the larger SC players in most cases succeeded in circumventing the sanctions, albeit with high costs. This may suggest that the official targets for sanctions (e.g. governmental military programmes) with their financial resources and lack of profitability considerations are even more likely to succeed in evading sanctions. 
To work towards their intended goals, sanctions need to be designed with an eye on the exact players and work processes they influence. Our research provides a rare entry into mapping these influence pathways.

\subsection{Limitations and Future Directions}

This research only begins to provide a theory on econo-political SC risks and much research can build on this early step. We focused on sanctions as an example, but this category of risks could be further expanded to include political instability, civil unrest, and other related areas of EPRs. More case studies could expand the portfolio of risks and responses, and further develop the relevant causal pathways. For example our limited data did not allow us to explicitly include the impact of sanctions on human resource flows of the firm; yet that may prove an important forth scope to be considered in how EPRs impact SCs.

Another limitation of this study is its reliance on qualitative data. While this type of data provides us with insights to propose a set of causal mechanisms that theorise on EPRs and their impact, we do not quantitatively assess these mechanisms. Empirical studies are needed to establish the magnitude of different risks and pathways and the effectiveness of different responses. Data availability is a major challenge to conduct such research due to less developed data collection processes in cases where EPRs are already present, and access challenges in the face of political sensitivities.

The time and costs associated with implementing each response should also be assessed and could be the target for analytical research. For example, operational research models could be developed to address optimum sourcing plans under different EPR portfolios. In coping with EPRs, manufacturing and 4PL members of our case SC where interested in analysing questions such as: when is the introduction of alternative suppliers cost effective? What should be the share of each supplier? What contractual arrangements best balance the risks and costs when exposed to EPRs and provide enough incentives for suppliers to continue working with the SC?

Finally, dynamic games between sanctioning countries and the sanctioned industries could also be developed from either perspective. Game theory can be used as a tool to help sanctioning countries to evaluate the effectiveness of their efforts, and can also be investigated from the sanctioned country's perspective to let companies compare solutions and devise better options to reduce the expected cost of potential risks. 
Overall, we hope this paper provides an entry into an important but largely unexplored research area and inspires others to explore different aspects of EPRs to SCs.

\section{Acknowledgement}

Authors would like to thank the guest editors Professors Sander de Leeuw, Dirk Pieter van Donk, René de Koster, and the two anonymous reviewers for their constructive comments, which helped to improve the paper significantly.

\section{References}

Askari, H.G., Forrer, J., Teegen, H. and Yang, J. (2003), Economic Sanctions: Examining Their Philosophy and Efficacy, Praeger Publisher, Westport.

Blos, M.F., Quaddus, M., Wee, H.M. and Watanabe, K. (2009), "Supply chain risk management (SCRM): a case study on the automotive and electronic industries in Brazil". Supply Chain Management: An International Journal, Vol. 14, No. 4, pp. 247-252.

Charnovitz, S. (2001), "Rethinking WTO Trade Sanctions", American Journal of International Law, Vol. 95, No. 4, pp. 792-832.

Chopra, S. and Meindl, P. (2007), supply chain management - strategy, planning \& operation, $3^{\text {rd }}$ Ed, Englewood Cliffs, NJ, Pearson Prentice Hall.

Davarzani, H., Zegordi, S.H. and Norrman, A. (2011), "Contingent Management of Supply Chain Disruption: Effects of Dual or Triple Sourcing". Scientia-Iranica, Vol. 18, No. 6, pp. 1517-1528.

Eisenhardt, K.M. (1989), "Building Theories from Case-Study Research". Academy of Management Review, Vol. 14, No. 4, pp. 532-550.

Eyler, R. (2007), Economic Sanctions: International Policy and Political Economy at Work, New York, Palgrave Macmillan.

Finch, P. (2004), "Supply chain risk management". Supply Chain Management: An International Journal, Vol. 9, No. 2, pp. 183-196.

Harland, C., Brenchley, R. and Walker, H. 2003. "Risk in supply networks". Journal of Purchasing \& Supply Management, Vol. 9, pp. 51-62.

Hoffman, D.G. (2002), Managing operational risk, New York, John Wiley and Sons.

Juttner, U. (2005), "Supply chain risk management: Understanding the business requirements from a practitioner perspective". The international journal of logistics management, Vol. 16, No. 1, pp. 120 - 141.

Kim, C.R. and Reynolds, I. (2011), Toyota stops work in Japan, delays launch of two models [Online]. Reuters. Available: http://www2.canada.com/story.html?id=4489758 [Accessed 12 May 2012].

Kleindorfer, P.R. and Saad, G.H. (2005), "Managing disruption risks in supply chain". Production and Operations Management, Vol. 14, No. 1, pp. 53-68.

Knemeyer, A.M., Zinn, W. and Eroglu, C. (2009), "Proactive planning for catastrophic events in supply chains". Journal of Operations Management, Vol. 27, No. 2, pp. 141-153.

Kovács, G. and Spens, K.M. (2007), "Humanitarian logistics in disaster relief operations". International Journal of Physical Distribution \& Logististics Management, Vol. 37, No. pp. 99-114.

Levary, R.R. (2007), "Ranking foreign suppliers based on supply risk". Supply Chain Management: An International Journal, Vol. 12, No. 6, pp. 392-394.

Lin, Y. and Zhou, L. (2011), "The impacts of product design changes on supply chain risk: A case study". International Journal of Physical Distribution and Logistics Management, Vol. 41, No. 2, pp. 162-186.

Martha, J. and Subbakrishna, S. (2002), "Targeting a just-in-case supply chain for the inevitable next disaster". Supply Chain Management Review, Vol. 6, No. 5, pp. 18-23. 
Mehari (2007), Risk Analysis Guide. Club de la Securite de l'Information Francais (CLUSIF).

Mollenkopf, D., Russo, I. and Frankel, R. (2007), "The returns management process in supply chain strategy". International Journal of Physical Distribution \& Logistics Management, Vol. 37, No. 7, pp. 568-592.

Monahan, S., Laudicina, P. and Attis, D. (2003) "Supply chains in a vulnerable volatile world". Executive Agenda, Vol. 6, No. 3, pp. 5-15.

Mullai, A. (2005), "A risk analysis framework for marine transport of packaged dangerous goods". In: Brindley, C. (ed.) Supply chain risk. Hampshire, England: Ashgate.

Norrman, A. and Jansson, U. (2004), "Ericsson's proactive supply chain risk management approach after a serious sub-supplier accident". International Journal of Physical Distribution and Logistics Management, Vol. 5, No. 34, pp. 434-456.

Norrman, A. and Lindorth, R. (2005), "Categorization of supply chain risk and risk management". In: Brindley, C. (ed.) Supply chain risk. Hampshire, England: Ashgate.

Paulsson, U. (2007), On managing disruption risks in the supply chain: the DRISC model. PhD Dissertation, Lund University.

Seuring, S.A. (2008), "Assessing the rigor of case study research in supply chain management". Supply Chain Management: An International Journal, Vol. 13, No. 2, pp. 128-137.

Silverman, D. (2000), Doing qualitative research: a practical handbook, London, SAGE publications.

Sinha, P.R., Whitman, L.E. and Malzahn, D. (2004), "Methodology to mitigate supplier risk in an aerospace supply chain". Supply Chain Management: An International Journal, Vol. 9, No. 2, pp. 154-168.

Sterman, J. (2000), Business Dynamics: Systems Thinking and Modeling for a Complex World, McGraw-Hill.

Tang, C.S. (2006), "Perspectives in supply chain risk management". International Journal of Production Economics, Vol. 103, No. pp. 451-488.

William, H.K. and Anton, D.L. (2003), "International Sanctions", Journal of Economic Perspectives, Vol. 17, No. 4, pp. 233-235

Wu, T., Blackhurst, J. and Grady, P.O. (2007) "Methodology for supply chain disruption analysis". International Journal of Production Research, Vol. 45, No. 7, pp. 1665-1682.

Yin, R. K. (2003), Case study research: Design and methods, London, Sage Publications. 


\section{Appendix A - Interview Guide (Translated into English)}

Interviewees received these questions as well as a brief description on goals of the interview meeting before each session.

\section{Primary interview (to define general directions of the research)}

Interviewee: -------- $\quad$ Company name: -------- Title in the company:

- What are the main risks in your company which can disrupt the operations of the chain? (Please exclude operational risks)

- What are the sources of main risks?

- According to your experience, how frequent those risks can happen?

- What is the potential loss they can make?

- Please describe those risks in more details. What happens to supply chain operations when those risks occur?

\section{Individual interview}

Interviewee: -------- $\quad$ Company name: --------- Title in the company: ---------

- Does the company consider risks originated from sanctions as significant? Why/why not?

- What are the risks which are originated from sanctions?

- What are the responses the company has taken to these risks?

- Which aspects of business are influenced by sanctions?

- How sanctions influence supply chain operations?

- How do you evaluate the impacts of risks caused by sanctions?

Focus group sessions

Participants:

Company name: Titles in the company:

- How each of the econo-political risks occurs in supply chain?

- What challenges do you face due to each risk?

- How do you fight against those challenges?

- Do you see any difficulties which can be triggered by taken reactions?

- How your company and also local members of the chain are influenced by those risk and reactions? 
- Do you see any specific factor which has a significant role on how risks can influence your chain's operations? 


\section{Appendix B - Analysis Process}

Data collection started by developing a primary conceptual framework based upon the literature and open interviews with three top managers of the studied cases. The first phase of data collection used individual interviews to learn about the companies, the type of EPRs they face and the resulting losses in previous years. Preliminary analysis sharpened the questions for follow up interviews and focus group sessions during the second phase of data collection. The main purpose of these meetings was to compare and aggregate the knowledge of different informants, leading to an increasingly detailed representation of relevant causal mechanisms. Data from each session was synthesised with previous findings using causal relationship diagrams and summary tables.

Besides building on the individual interviews we utilised the group sessions in developing these causal diagrams. Before each group session participants were provided with a short document describing the core topics of discussion and definitions for key terms used within the group sessions. Different risks were identified before the sessions, yet participants were also able to modify and extend these risks within the session. Earlier group sessions focused on identifying the challenges that emerged as a result of EPRs. Discussions started with open-ended questions on how each risk occurs and how it influences SC operations. The first author facilitated the sessions, capturing the emerging themes on a board, asking probing questions to establish causal mechanisms, and helping to keep the discussion focused. Later sessions followed a similar structure but focused on solutions and downstream impacts to discover what outcomes each solution has contributed to. These discussions were largely informed by the direct experience of participants, but in a few instances hypothetical scenarios were explored to predict potential downstream outcomes which had not yet materialised.

The resulting summary figures and tables were then shared with participants to collect feedback and elaborations. The analysis was finalised in the third step in which the unfolding of new risks and company reactions were monitored through follow ups and company reports. Further triangulation was attempted through direct observation and monitoring of the sourcing decisions in practice. 


\section{Appendix C - Building confidence in the results}

Different actions were taken to ensure the quality and rigor of this research. Early-on a case study protocol was developed that guided the different steps of the research and helped with organising the research trajectory (Yin, 2003). Construct validity was partially addressed by engaging four case informants to review the intermediate progress reports and to provide feedback on the accuracy of the interpretations (Yin, 2003; Seuring, 2008). Furthermore, drawing on multiple sources of data helped with triangulation between different types of evidence and provided some external validity (Silverman, 2000). The research process employed a combination of process guides to enhance accuracy (Silverman, 2000): the first author conducted the observations and took short notes, expanding upon them afterwards to develop a body of evidence based on direct observation; a field work journal was kept to prevent forgetting critical days, specific people who were met and the data collected; consulting the relevant literature provided additional guidance in the research process; and finally, multiple criteria for assessing the trustworthiness in qualitative research (Mollenkopf et al., 2007, Lin and Zhou, 2011) were used to build confidence in the research process at different steps. These considerations are summarized in Table A.

Table A- Criteria to ensure trustworthiness of the study and findings

\begin{tabular}{|c|c|}
\hline Criteria & Employed methods in this study \\
\hline Credibility & Research protocol was prepared in early stages of the work. \\
\hline $\begin{array}{l}\text { Results are be acceptable } \\
\text { representations of the data }\end{array}$ & $\begin{array}{l}\text { Connection between research questions and required data to gather was } \\
\text { defined in research design. } \\
\text { Case study report was written based on a pre-defined. } \\
\text { One experienced academic researcher and informant in the case company } \\
\text { gave input to researchers all the way during research process } \\
\text { The initial interpretations of the data were checked with interviewees in the } \\
\text { companies } \\
\text { Finalized interpretations of data were checked with key contacts in the case } \\
\text { companies } \\
\text { The emergent framework and propositions were expanded and altered } \\
\text { several times to match the data in the best way }\end{array}$ \\
\hline $\begin{array}{l}\text { Dependability } \\
\text { Explanations are stable or } \\
\text { consistent; findings are not } \\
\text { unique to time and place }\end{array}$ & $\begin{array}{l}\text { The study has been done during four years to investigate the case companies } \\
\text { through the time. } \\
\text { The interviewees were selected among experienced managers who have been } \\
\text { completely familiar with past and present status of the companies. } \\
\text { Regardless of the time and specific characteristics of sourcing methods in } \\
\text { investigated companies, narrated stories of risk were consistent. }\end{array}$ \\
\hline $\begin{array}{l}\text { Confirmability } \\
\text { Interpretations are the result of } \\
\text { the participants and the } \\
\text { phenomenon and are not }\end{array}$ & $\begin{array}{l}\text { Interpretations, preliminary findings and analysis were independently } \\
\text { reviewed by all the researchers. } \\
\text { Provisional interpretations were reported to key informants of the case }\end{array}$ \\
\hline
\end{tabular}




\begin{tabular}{l} 
Criteria \\
\hline biased to researchers' ideas
\end{tabular}

\section{Integrity}

Interpretations are not influenced by misinformation or evasions by participants

Fit

Findings fit with the substantive area under investigation

Understanding Participants accepts the results as representations of the reality

Generality

Findings discover multiple aspects of the phenomenon

Control

Organizations can influence aspects of the theory

\section{Employed methods in this study}

companies through the process of research.

The interviews and focus group sessions were completely friendly and anonymity of interviewees are kept in all reports.

The participants were willing to contribute because the focus of the work was their daily issue and an important aspect to consider in their business. One interviewee evaded from answering some of the questions, the interpretation of gathered data from him was checked with other informants in the company.

Final analysis was reviewed by four external experts in the area. This criterion was also addressed based on the methods mentioned in credibility, dependability and confirmability criteria.

The emergent results are describing the investigated area deeply and completely based on the experienced events in the studied cases.

At the end of each interview and focus group meeting, participants were asked to either confirm or correct the interpretations of researchers.

After each interview and focus group meeting, an extended report was sent to participants to make sure about the correctness of interpretations.

Periodic reports were sent to key informants of each stage of the work to get their confirmation.

Final report was reviewed and confirmed by one of the key members in the studied case.

Semi-structured and open-ended interviews and focus group sessions let participants to consider multiple aspects in the area.

Informants from different departments were interviewed to capture different aspects of the investigated phenomenon.

The study has been done during a long period of time which let researchers to grasp multiple insights through the time not only from interviewees but also the documents in the companies.

Some aspects of the studied concept can be controlled by investigated companies, e.g. SC mitigation strategies and decision making process in case of occurrence of risky events.

Sources of criteria: adapted from (Mollenkopf et al., 2007, Lin and Zhou, 2011) 


\section{Appendix D - Cause and effect diagram for EPRs' impact, SC response, and downstream effects}

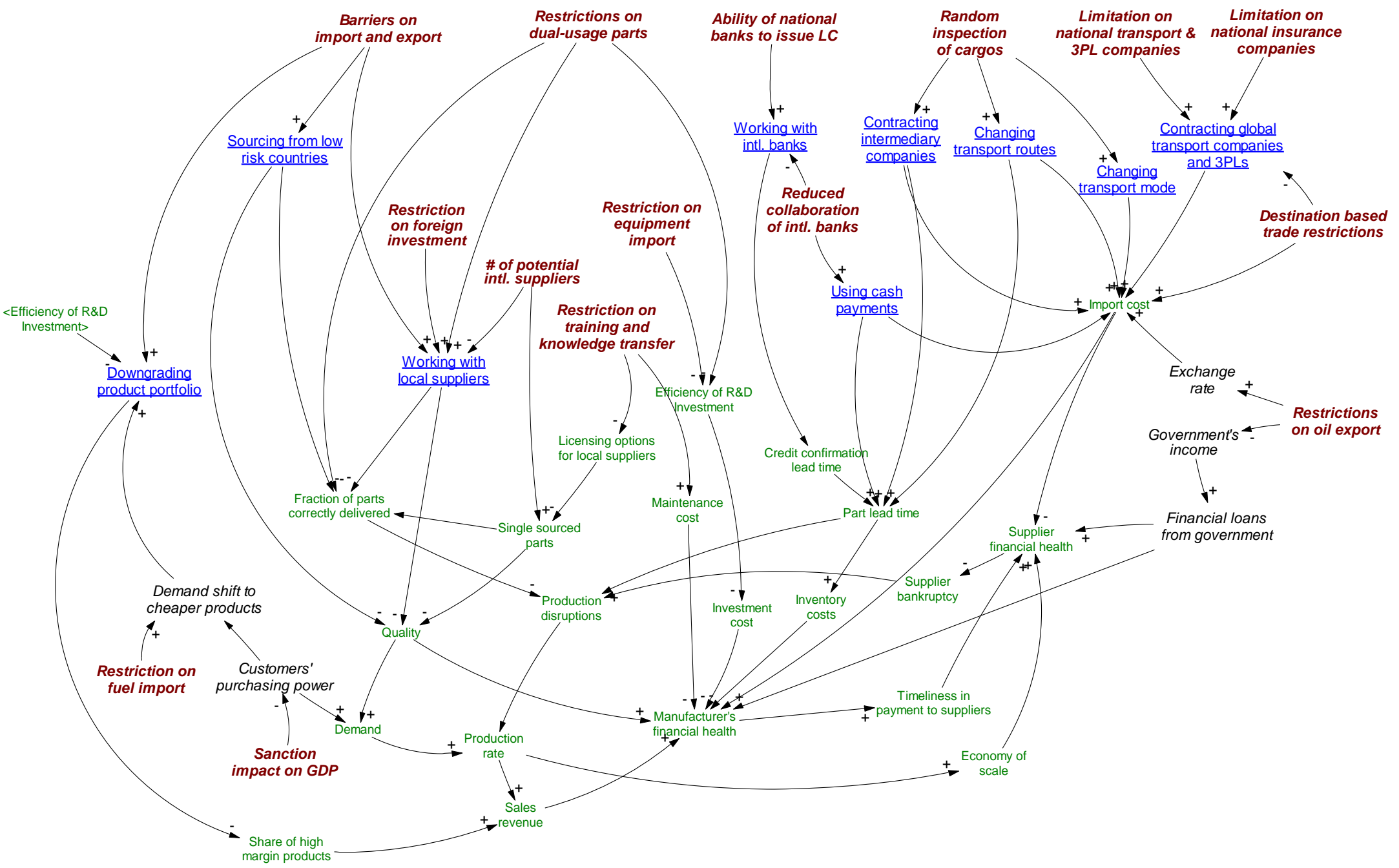

